\title{
AS APLICAÇÕES DA INFORMÁTICA NO ENSINO DE QUÍMICA COMO ALTERNATIVA PARA O ENSINO E APRENDIZAGEM
}

\author{
THE APPLICATIONS OF COMPUTER SCIENCE IN THE TEACHING OF CHEMISTRY AS AN \\ ALTERNATIVE FOR TEACHING AND LEARNING
}

\author{
Rafael Soares Silva \\ Universidade Cruzeiro do Sul, São Paulo, Brasil. E-mail: doc.rafaelsoares@gmail.com \\ https://orcid.org/0000-0001-9994-6653
}

DOI: https://doi.org/10.46550/amormundi.v1i2.31

Recebido em: 16.09.2020

Aceito em: 04.11.2020

\begin{abstract}
Resumo: A presente pesquisa analisou as aplicaçôes da informática ou da Quimio-informática como uma alternativa de ensino que pudesse auxiliar os professores e alunos no processo de Ensino e aprendizagem. Os temas tratados nessa pesquisa procurou também trazer a Quimio-informática como uma alternativa de ensino que pudesse auxiliar os professores a incorporar essa nova ferramenta a sua prática. Na tentativa de avançar. Essa tendência é mesclar ambientes presenciais com virtuais, um complementando o outro, promovendo o desenvolvimento de metodologias de trabalho e recursos mediadores. Os professores devem se inserir neste novo cenário educacional, a fim de poder propiciar uma maior interação com seus educandos. $\mathrm{O}$ mercado disponibiliza ferramentas computacionais, softwares de simulaçóes os quais estão presentes cada vez mais no ambiente educacional. São múltiplas as funcionalidades deste recurso, por isso sua inserção no ambiente escolar para auxiliar o professor no processo de construção do conhecimento Químico com mais eficiência.
\end{abstract}

Palavras-chave: Ensino de Química. Quimio-informática. Química computacional.

\begin{abstract}
The present research analyzed the applications of informatics or Chemo-informatics as a teaching alternative that could assist teachers and students in the process of Teaching and learning. The themes dealt with in this research also sought to bring Chemo-informatics as a teaching alternative that could help teachers to incorporate this new tool into their practice. In an attempt to move forward. this tendency is to mix face-to-face and virtual environments, one complementing the other, promoting the development of work methodologies and mediating resources. Teachers must be inserted in this new educational scenario, in order to be able to provide a greater interaction with their students. The market offers computational tools, simulation software which are increasingly present in the educational environment. There are multiple functionalities of this resource, so its insertion in the school environment to assist the teacher in the process of building chemical knowledge more efficiently.
\end{abstract}

Keywords: Chemistry teaching. Educational Game. Chemical balance 


\section{Introduçáo}

e início, deve-se compreender que um software não funciona automaticamente
como desencadeador do processo de aprendizagem. Em outras palavras, o sucesso de um software em promover aprendizagem depende de sua integração ao currículo e às atividades da sala de aula.

O professor deve inserir em seu material de ensino o uso de recursos midiáticos para dinamizar as aulas, os Parâmetros Curriculares Nacionais-PCN (1998) para o ensino de Química revela uma visão já direcionada para este recurso. A sociedade e seus cidadãos interagem com o conhecimento químico por diferentes meios e por muitos anos os professores desta disciplina apenas direcionavam seus alunos a imaginar as moléculas, as interaçôes; com a inserção dos laboratórios multidisciplinar nas escolas públicas, estes ganharam uma ferramenta didática muito significativa, o uso de materiais alternativos para realizar práticas de ensino tornou o cotidiano do aluno algo mais interessante.

Estamos vivenciando a era da Informática, Kenski (2007) revela que na atualidade, as tecnologias invadem o nosso cotidiano e alteram a forma de observar o mundo. Em decorrência desse momento o professor passou a necessitar de uma reformulação em seu pensar pedagógico. Este precisa encontrar novas metodologias para suas aulas com uso da informática. Os softwares educativos deveriam ser construídos sob os aportes de uma teoria sobre a maneira com que os sujeitos aprendem.

Portanto, o educador de Química que se encontra disponível a novos olhares educacionais, pode lançar mão desta nova ferramenta e direcionar o aluno a criar conhecimento. Softwares como o CHEMSKETCH, CROCODILE, disponibilizam plataforma de criação molecular em duas ou até três dimensóes além de simular práticas laboratoriais para localidades em que falta um laboratório.

Quimio-informática é uma área interdisciplinar que envolve a Química e a Informática e consiste no uso de técnicas computacionais aplicadas a uma gama de problemas no campo da Química. Essas técnicas são utilizadas em companhias farmacêuticas no processo de descoberta de medicamentos. Esses métodos podem também ser utilizados de várias formas em indústrias químicas e centros acâdemicos.

Ninguém sabe ao certo quando começou o desenvolvimento da Quimio-informática, mas alguns autores, como por exemplo Johann Gasteiger afirmam que a Quimio-informática foi se desenvolvendo durante os últimos 40 anos e atingiu o seu ápice apenas nos últimos 10 anos.

O termo foi definido em 1998 por Frank Brown:

Chemoinformatics is the mixing of those information resources to transform data into information and information into knowledge for the intended purpose of making better decisions faster in the area of drug lead identification and optimization.

Pode-se dizer que o desenvolvimento da Quimio-informática teve o seu início na década de 60, mais precisamente em 1965 com a publicação do algoritmo de Morgan que é um algoritmo utilizado no Chemical Abstracts Service com o intuito de gerar um identificador numérico único para cada estrutura química conhecida.

Uma dos primeiros desafios da Quimio-informática foi encontrar uma maneira de se 
representar uma estrutura química de forma que fosse tangível por uma máquina. Diversos algoritmos foram desenvolvidos com este fim, sendo que as representaçôes em linha e de matriz de conectividade são as mais populares e utilizadas por diversos software

A informática organiza nossa vida, nosso trabalho, o nosso dia a dia, devemos nos informar cada vez mais, e procurar o jeito mais fácil de organizar. As indústrias de informática vêm desenvolvendo políticas que buscam o desenvolvimento de (hardware) e software, enfim tudo isso engloba os altos níveis de informação e tecnologia, caracterizando em nível científico a Químio-informática.

A Quimio-informática é uma área emergente que utiliza métodos computacionais para resolução de problemas de Química. Têm sido intensamente utilizada pela indústria química, Centros de Ensino acadêmico e Farmacêutica na descoberta de novos produtos e tem trazido interpretaçôes novas a questôes científicas fundamentais. Diante de tantas possibilidades, o motivo do presente estudo, teve interesse em pesquisar quais as aplicabilidades da Informática no Ensino de Química.

A formação de professores ainda é um gargalo, para o desenvolvimento de novos conhecimentos e de novas técnicas de ensino que possam melhorar a qualidade do ensino. Mesmo com alguns investimentos pelo governo Federal, Estaduais e Municipais ainda é insipiente a procura de jovens do último ano do ensino médio para as Licenciaturas, principalmente nas áreas de Química, Física, Biologia e Matemática, consideradas campeâs de falta de professores no Brasil.

As Faculdades e Universidades Brasileiras têm oferecido cursos áreas, mas a procura nos vestibulares tem deixado muitos estados sem professores nessas áreas, o que os pesquisadores têm alertado para um apagáo de professores, e apresentam como alternativa a formação de técnicos e tecnólogos nas áreas para suprir as necessidades das escolas, uma vez que em muitos estados faltam esses profissionais, o que acarreta perda para os alunos, principalmente para os que vão prestar vestibulares e concorrer para vagas nas universidades.

\subsection{A Informática como instrumento mediador do ensino de Química}

Em áreas, como a Química, a prática de ensino pode ser favorecida pela experimentação como ferramenta instrucional. A aprendizagem de muitos conceitos químicos é favorecida quando ocorre abordagem experimental. Este aspecto deve ser aproveitado como agente facilitador da interaçáo professor-aluno embora represente dificuldades de ordem material que tornam a experimentação proibitiva em escolas com poucos recursos.

É importante avaliar como a utilização do computador pode contribuir no processo educacional já que, na tentativa de contextualizar a teoria e a prática no ensino de Química, a utilização de recursos computacionais nas aulas pode representar uma alternativa viável. Um tipo de programa de informática que pode ser usado com fins didáticos é representado pelos programas de simulação que permitem destacar aspectos específicos do conteúdo abordado e orientar a tomada de decisóes em experimentos, situação que favorece muito a compreensão dos conceitos químicos.

A experiência da utilização de programas de informática no ensino médio, é cada vez mais presente em escolas do Brasil, considerando o aspecto instrucional do uso do computador 
no ensino de Química, a utilização de programa de computador, o Model ChemLab, simula as atividades experimentais de aulas práticas em "laboratório virtual". Este programa é um produto comercial de baixo custo, que requer configuraçóes pouco sofisticadas e algumas adaptaçóes para o idioma português. Outro aspecto direcionador da proposta de utilização deste recurso didático visa atender a necessidade de proporcionar uma mínima noção de informática a estudantes de escolas públicas.

Com um treinamento rápido, porém considerado suficiente pela maioria dos professores que já utilizam essa ferramenta, e para familiarização com o programa e habilitação para o desenvolvimento da atividade em condiçóes satisfatórias, considerando ainda que poucos estudantes utilizam o computador porque muitas escolas dispóem de laboratório, porém falta ser instalado completamente e que a maioria dos alunos tem interesse em participar da atividade didática de Química usando computador tendo em vista a oportunidade de receber treinamento em informática.

A adaptação do "ChemLab" envolve a criação de textos em português, levando em consideração as dificuldades dos alunos e professores, em traduzir para o português o programa. O conteúdo das novas experiências simuladas foi criado a partir do conteúdo dos livros utilizados como material didático de apoio das aulas. Desta forma, a proposta pode ser inserida no ambiente de sala de aula sem interferir no ritmo de aulas programado no planejamento escolar. A interferência era indesejada por representar eventuais prejuízos para a disciplina e por dissociar a proposta da realidade do processo de ensino/aprendizagem do objeto da pesquisa.

O professor dever ter disponível para atividades didáticas, os microcomputadores, localizados no laboratório de informática, onde acontecem atividades práticas relacionadas às disciplinas de Química. As aulas podem ser organizadas seguindo o cronograma inicial estabelecido no planejamento escolar.

Pode-se também optar pela utilização do programa paralelamente às aulas com atividades práticas. Para manter o rendimento das aulas, tendo em vista inclusive a infraestrutura disponível, as classes constituídas em média por 40 alunos podem ser organizadas em grupos de 5 integrantes, garantindo o acesso de todos os alunos aos computadores, enquanto os demais acompanhavam a atividade assistindo alguns vídeo ligado ao assunto em questão pela televisão.

Os resultados obtidos com a introdução do material desenvolvido podem inclusive servir de subsídio para outras escolas e professores, podendo ter um considerável ganho no rendimento das aulas, no interesse dos alunos e melhora no desempenho geral dos alunos na avaliação.

Pode-se notar que a utilização de computadores em aulas de Química no ensino médio é viável considerando-se o conteúdo da disciplina, a capacitação de professores e a adequação dos recursos de informática disponíveis. Os resultados da introdução didática dos recursos de informática poder ser muito positivas mesmo em condiçôes materiais pouco favoráveis, comuns nas escolas públicas. Isto estimula novas iniciativas viáveis que não envolvem altos custos e respondem a expectativas dos estudantes que merecem ser atendidos sendo que a participaçáo dos professores, após breve treinamento, é fundamental para que bons resultados possam ser alcançados e deve ser encorajada para benefício de todos.

Mas, então, como as professoras e professores poderiam "usar" essas ferramentas tecnológicas, isto é, o computador e a Internet em suas salas de aula para ensinar química? 
Como esses ambientes virtuais, isto é, os softwares educacionais e a páginas da web ou WWW, poderiam ajudar aos alunos a aprender química?

Além do problema metodológico, é importante destacar que esses recursos não estão, de maneira alguma, disponíveis em todas as escolas, bem como, a maioria de professoras, professores e alunos do ensino médio ainda não têm acesso a essa tecnologia.

Os programas de modelagem, simulação e de bases de dados permitem interatividade entre usuário-conhecimento, o que pode possibilitar ou facilitar uma aprendizagem significativa dos conteúdos químicos. Da mesma forma, com os programas chamados sistemas especialistas e realidade virtual, pode ser possível estabelecer uma nova forma de relacionamento alunoconhecimento químico, superior a atingível por meio impresso normal ou através da aula expositiva tradicional.

O Journal of Chemical Education - JCE, entre 1977 e 1994, foram listados 488 programas, classificados de acordo com doze categorias propostas. Também foi feito o mesmo levantamento de 1978 a 1994, na Química Nova - QN, onde foram encontrados 51 programas para ensino de química. Tais programas são usados de muitas maneiras no processo de ensinoaprendizagem: do simples exercício e prática de problemas numéricos e tutoriais de conceitos, que avançam sob o controle do aluno aos softwares de modelagem molecular, aos complexos sistemas especialistas, baseados em inteligência artificial e softwares de realidade virtual que permitem uma nova relação aluno-conhecimento.

A pesquisa relacionou o desenvolvimento do hardware com o software educacional, que foi sendo desenvolvido para o ensino de química ao longo de 18 anos. Ficam evidentes as mudanças dos programas: de simples cálculo computacional e tutoriais, ou seja, poucos interativos às simulaçôes e bases de dados / modelagem e / ou simulação com previsão, que permitem boa interação aluno-conhecimento.

Os conteúdos mais abordados nos programas do JCE e da QN e dos tipos mais frequentes. Os conteúdos mais trabalhados foram: química quântica/teoria quântica; análises qualitativa, quantitativa, gravimétrica, volumétrica, titulométrica; espectrofotometria, espectroscopia: RNM, EPR; termodinâmica; estruturas, o que totaliza cerca de 49,3\% dos programas, e o tipo de maior frequência foi o cálculo computacional, seguido muito de longe por simulação e tutoriais.

Quanto aos sites da Internet, esses aparecem a partir de 1995 no JCE e depois na QN no ano de 1998. Entre os autores nacionais que se dedicaram ao estudo do potencial das tecnologias interativas no processo ensino-aprendizagem de química, pode-se destacar: Vieira (1997), Ferreira (1998), Eichler (1999) e Giordan (1999). Os dois últimos com várias publicaçôes na Revista QN na Escola, que é dedicada à divulgação de pesquisas sobre educação química, principalmente, para o ensino médio.

\subsection{Refletindo sobre Tecnologia, Educação e Informática}

Ao dar início a uma discussão sobre ciência e tecnologia convém ressaltar o que assinala Frigotto (1991):

É importante demarcar que são os homens em relação social que definem e produzem a ciência e a tecnologia. Nem a sua produção, nem a sua aplicação ao processo produtivo, é um dado arbitrário. São produtos humanos marcados pelas 
relaçôes sociais (econômicas, políticas, culturais, éticas). Em nossa sociedade, são produtos resultantes de relaçóes sociais de classe. A ciência e a técnica são, portanto, dominantemente produzidas no interior de relaçóes marcadas pela exploração e exclusão social.

As crescentes mudanças que têm ocorrido no mundo do trabalho, como consequência dos avanços tecnológicos, tem gerado uma forte tendência à adaptação imediata do projeto educacional às regras do mundo da produção. Deve-se ter o cuidado ao analisar as consequências da incorporação de novas tecnologias pelas empresas e o papel que a educação deve aí desempenhar, para evitar a apropriação acrítica de propostas educacionais que visam a incorporaçáo dos avanços tecnológicos.

A afirmação de que as novas tecnologias tendem e devem incrementar requisitos de escolaridade é polêmica, pois se deve realizar uma crítica ao discurso que leva a "depositar "na área educacional uma responsabilidade que não lhe cabe exclusivamente, pelo desenvolvimento econômico e pela modernização da produção no país.

É inegável que a introdução de novas tecnologias e de novas formas de organização do trabalho tem gerado modificaçôes no processo de trabalho mudando o seu conteúdo, mas permanecendo a relação social capitalista. É necessário que se entenda a ciência, a técnica e a tecnologia como resultado da atividade humana, fruto das relaçóes históricas e sociais para que possamos situar os processos produtivos e o papel da escola nesse embate. Não se trata de adaptar o projeto educacional às novas exigências do mercado de trabalho e sim, romper com a concepção mercadológica e imediatista de educação.

Retomando: o avanço acelerado das inovaçôes tecnológicas vem sendo hoje palco de atores e expectadores, ora otimistas que defendem o seu uso como fonte libertadora dos esforços e dos trabalhos rotineiros e, ora pessimistas cujos argumentos denunciam a alienação do trabalho, o esgotamento de recursos e a destruição do caráter humano nas relaçôes entre os homens. Para os defensores do primeiro grupo a tecnologia permite aumentar a produçáo de bens com menos esforço e a sua adoção seria inevitável.

Os pessimistas embora concordem com a inevitabilidade da adoção da tecnologia, defendem que seus esforços são negativos, destruindo e desumanizando as relaçôes sociais. Essas duas posturas também seriam adotadas em relação à educação e ao uso da tecnologia na escola como forma de melhor qualificar o aluno para as novas exigências do mercado de trabalho, ou ao contrário, de excluir o seu uso pelo "fetiche" de que sob a" lógica do capital" a sua influência sobre a escola seria sempre nefasta (FRIGOTTO, 1991).

Um ponto a ser observado é de que a degradação do trabalho não é um resultado inevitável da tecnologia, embora o avanço tecnológico náo seja neutro e sim produto de relaçóes sociais, históricas e concretas. É preciso considerar as contradiçóes existentes no uso e no avanço da tecnologia a fim de definirmos o espaço da escola e a formação científica e técnica dos alunos. A tecnologia se constitui - como afirmamos - em "força do capital”, porém, as mudanças decorrentes de sua utilização apresentam uma positividade que precisa ser considerada.

No plano educacional as inovaçóes tecnológicas não devem servir para ressuscitar o tecnicismo de outrora, apenas com a finalidade de atender às exigências do mercado de trabalho. Não se deve configurar como adestramento, puro e simples, e sim, como busca de redirecionamento do sentido da tecnologia para que atenda aos interesses e necessidades dos 
setores dominados da sociedade.

As instituiçôes sociais não podem excluir, por muito tempo, componentes culturais da vida cotidiana, ou seja, quanto mais as novas tecnologias de informação e comunicação se tornam presentes na cultura cotidiana, mais elas tendem a ser incorporadas aos processos escolares. Papert (1994) alerta para a estagnação da escola e sua dificuldade em incorporar as mudanças da ciência e da tecnologia:

A escola é um notável exemplo de uma área que não mudou tanto. Pode-se dizer que não houve qualquer mudança na maneira que nós distribuímos a educação aos novos estudantes (...) o nosso sistema de escolaridade mudou, mas náo de uma forma que tenha alterado sua natureza (...). Por que durante um período em que tantas atividades humanas foram revolucionadas, não vimos mudanças comparáveis na forma como ajudamos nossas crianças a aprender?

Se a meta, ao lidarmos com essa nova tecnologia, é o domínio da máquina e não simplesmente seguir receitas e instruçóes, a mera apresentação do computador e das operaçôes instrumentais para o seu uso é insuficiente e não aumenta, necessariamente, a autonomia nem estimula a criatividade. Muito pelo contrário, torna-se dessa forma (reforça) uma relação tão robotizada e massificante quanto às velhas tecnologias educacionais, ou idealista e mecânica.

Por mais que desconheçamos os mecanismos de funcionamento dessas "máquinas", por mais que não dominemos essa nova linguagem, a informatização não está mais restrita aos campos da engenharia, invadiu todas as áreas do conhecimento e se mostra presente no nosso cotidiano, sob sua forma mais simples como o nosso "hollerit", o extrato de nossa conta bancária, os bancos 24 horas. A maioria dos setores da sociedade brasileira está sendo informatizados, seja na área de produção ou prestação de serviços. É preciso formar cidadãos com capacidade para atuarem em uma sociedade brasileira, altamente marcada pela tecnologia. O que deve ser considerado é a questão "como" e "quando" as novas tecnologias devem ser incorporadas pela escola.

Segundo Apple (1995) o debate sobre o papel da nova tecnologia na sociedade e nas escolas não é e não deve ser apenas sobre a correção técnica do que os computadores podem e não podem fazer. Essas podem ser, de fato, as questôes menos importantes. No centro do debate, ao invés, estão as questôes éticas e ideológicas relacionadas com o que as escolas devem ser e os interesses de quem elas devem servir"

Não podemos deixar de considerar também que tanto a educação quanto a tecnologia, compreendem processos culturais estritamente ligados ao processo produtivo e aos interesses políticos. É preciso redirecionar incrementos tecnológicos para o atendimento dos interesses e necessidades dos setores dominados da sociedade, e que constituem a maioria da população brasileira. Portanto, reconhecer o que acontece dentro e fora da escola é central para se compreender o que irá acontecer com as novas tecnologias na educação

\section{Metodologia}

Visando contribuir para a melhoria do Ensino de Química, essa pesquisa possui uma abordagem qualitativa, de natureza metodológica bibliográfica. Bogdan e Biklen (1994) destacam que, em pesquisas qualitativas, os dados coletados são predominantemente descritivos, a preocupação com o processo é muito maior do que com o produto e a análise dos dados tende a seguir um processo indutivo. 
Considera-se que essa pesquisa possa servir de subsídio para outros trabalhos, como também auxiliar os professores de Química, a utilizarem a ferramenta computacional como aliado no ensino e pesquisa de novas atividades para ensinar e aprender Química, de forma mais prazerosa e eficiente, dando oportunidade para que alunos e professores possam descobrir novos conhecimentos. Preocupou-se também em explicitar como a informática pode melhorar o ensino de Química através da compreensão do fenômeno educativo sob a ótica de novas tecnologias, que podem subsidiar a prática pedagógica do professor.

\section{Resultados e discussáo}

Sob o nome de Química Computacional entende-se, de um modo geral, o domínio dos métodos computacionais aplicados à Química. Dado que existe um largo número de procedimentos computacionais, a Química Computacional apresenta-se como um domínio interdisciplinar, ramificando-se pelas diferentes áreas em que, tradicionalmente, é costume dividir a Química (Químico-Física, Química Orgânica, Química Farmacêutica, Bioquímica, Química Inorgânica, Química Analítica, Química Tecnológica, etc.) e, também, pela Ciência dos Computadores.

Nos últimos 25 anos muitas das áreas de aplicação da Química Computacional sofreram um desenvolvimento significativo devido ao aparecimento de novos computadores, de software sofisticado e de uma melhor compreensão dos princípios básicos. O potencial oferecido pela atual tecnologia de hardware e software teve como consequência o desenvolvimento de uma grande variedade de técnicas para cálculos numéricos e simbólicos. Esses métodos abriram muitas áreas de aplicação e o aumento espetacular do potencial da referida tecnologia que torna a Química Computacional um dos domínios interdisciplinares mais promissores na direção do século XXI.

Esses desenvolvimentos modificam a rotina do ensino de química: atualmente, os cálculos químico-quânticos são essenciais em qualquer laboratório acadêmico. Sendo assim, a química computacional torna-se capaz de fornecer resultados confiáveis sobre geometria molecular e outras propriedades, que são provenientes de experimentaçóes químicas ou derivados de abordagens puramente teóricas, podendo ser obtidas através de métodos de mecânica molecular, mecânico-quântico e pela metodologia do funcional da densidade" (LIMA, 2010)

A Química Computacional é um vetor na direção da unificação. Ao identificar- se como um domínio interdisciplinar com base num onipresente instrumento laboratorial - o computador -, é a ferramenta capaz de tratar simultaneamente a modelação quântica e clássica, a geometria e a informação química. Esta característica essencial e, porventura, única fez surgir uma nova comunidade científica baseada na habilidade do computador para resolver problemas químicos e na reunião de cientistas de diferentes áreas, tradicionalmente separadas. A interação entre eles tem conduzido a realizaçóes científicas e tecnológicas de grande importância, bem como ao estímulo de novas gerações de jovens investigadores.

As bases da interpretação de todos os fenômenos químicos residem nos princípios unificadores das Mecânicas Quântica, Clássica e Estatística e da Geometria (melhor dizendo, das Geometrias), sejam quais forem às áreas tradicionais da Química: Inorgânica, Orgânica, Química-Física, Química Analítica, Bioquímica, etc. Essas bases estão, atualmente, bem estabelecidas e conduzem a cálculos quânticos que englobam problemas tão importantes como 
a reatividade química, espectroscopia, mecânica e dinâmica moleculares.

As simulações quânticas e clássicas, baseadas nos métodos de Monte Carlo, dinâmica molecular e dinâmica browniana, são ferramentas indispensáveis no estudo dos estados sólido e líquido, de misturas de sistemas simples e complexos, assim como no teste de potenciais, intra- e intermoleculares, e de teorias mecânico-estatístico.

Adicionalmente, qualquer dessas áreas, quer numa perspectiva fundamental, quer numa perspectiva de aplicaçóes bioquímicas e tecnológicas, confronta-se, atualmente, com o problema do tratamento de quantidades brutais de informação. Esse problema pode, também, ser resolvido de uma forma unificada no âmbito da Química Computacional. Assim, os métodos de aquisição e processamento de dados com vista à obtenção de conclusôes finais, ou de decisôes vitais, são atualmente um dos objetivos da Química Computacional. Esses métodos são, normalmente, catalogados sob nomes sonantes como Quimiometria, Redes Neuronais, Sistemas Inteligentes, Algoritmos Genéticos, Geometria Fractal, Grafismo Molecular, etc.

As enormes bases de dados de compostos químicos - mais de 14 milhóes de compostos estão atualmente identificados e registrados -, acompanhadas de dados obtidos por variadíssimas técnicas (Infravermelho, Raman, RMN, Espectrometria de Massa, Cromatografia, etc.) e de outras informaçóes específicas, só podem ser manipuladas, de uma forma unificada, pela presente tecnologia computacional. A manipulação dessas bases de dados conduz à resolução de uma enorme gama de problemas: planejamento de sínteses, relaçóes quantitativas de estrutura-reatividade, projeção de potenciais eletrostáticos, análise de dados espectroscópicos, reconhecimento de estruturas químicas, análise de populaçóes, etc.

\subsection{A Quimio-informática}

$\mathrm{Na}$ gestão de informação, computação, comunicação e edição, a interface informática e Química tem sido empregada com uma especificidade muito própria. Nos laboratórios de Química, os softwares mostram-se como ferramentas imprescindíveis para a realização das análises o que tem possibilitado o desenvolvimento constante de novas metodologias o que exige além da formação em Química sólidos conhecimentos de Informática.

Nos últimos anos tem se notado uma sofisticação das técnicas de computação em Química e essas ferramentas que invadiram gradualmente os laboratórios exigindo muitas vezes que o profissional tenha conhecimentos do software ou equipamento para a realização de relatórios, manusear um espectro, fazer pesquisa bibliográfica, analisar resultados obtidos, fazer previsóes para os problemas que tem em mão entre outros.

A fronteira entre a Química e a Informática (Cheminformatica), que tem por finalidade o desenvolvimento de sistemas de informação, métodos estatísticos, algoritmos entre outros. A "Química Computacional” é uma expressão ainda usada como sinônimo, embora seja normalmente conotada com a utilização de softwares.

A procura de especialistas nessa área, ou seja, profissionais que além dá sólida formação em Química domine os sistemas de análise tem sido um grande gargalo para as indústrias química e farmacêutica que fazem investigação de novos produtos e que utilizam nesse processo métodos computacional e técnicas intensivas baseadas em informação.

Tradicionalmente tem-se exigido aos químicos 'conhecimentos de informática na óptica 
do utilizador' e, mesmo esses, não lhes são normalmente fornecidos pelas universidades que frequentam. Conhecimentos e capacidades muito mais vastos nesta área vão ser necessários no futuro próximo à medida que os métodos computacionais em Química se desenvolvem e estabelecem que o volume de informação química disponível comece a ser reconhecido e que a instrumentação gera e arquiva mais e mais dados.

A computação vai rapidamente permeando os métodos de decisão, as técnicas laboratoriais, os métodos de avaliação de resultados. Se numa primeira fase o fenômeno se centrou na indústria de inovação aplicada, ele vai estender-se ao ensino, à investigação fundamental, à otimização de processos e aos sistemas de controle de qualidade, áreas que empregam a maioria dos químicos.

Onde ir buscar profissionais com competências nesta área? O problema existe há décadas, em pequena escala, nos grupos acadêmicos pioneiros da Quimio-informática. Nessa primeira geração recorreu-se normalmente a químicos que adquiriram conhecimentos de informática de forma mais ou menos estruturada. O problema estendeu-se à indústria, em grande escala, quando esta adotou metodologias computacionais, e tem sido resolvido por químicos com formação complementar em matemática ou informática.

No contexto atual exige-se uma resposta mais sistematizada por parte das instituiçóes de ensino e, nos EUA e Reino Unido, estão criando cursos de mestrado em Quimio-Informática e cadeiras nesta área a incluir nos cursos de graduação.

A criação de disciplinas de Quimio-informática nas Licenciaturas de Química, é urgente. Já a criação de mestrados será provavelmente demorada sua implantação no Brasil, o recrutamento para este campo, de licenciados em Química, será sempre uma estratégia com poucos frutos. Sempre serão raros os químicos que, depois de uma licenciatura em Química de 4 ou 5 anos, decidirem entrar numa área com tão forte componente de Informática. O mesmo problema acontece em Biologia, para encontrar cientistas na área da Bio-informática.

Por outro lado, seria muito mais fácil propor aos finalistas do ensino Médio uma Licenciatura em Bio- e Quimio-informática cujos conteúdos principais seriam a Química, a Biologia e a Informática. A licenciatura daria formação básica em Biologia e em Química, com ênfase na instrumentação e nas aplicações informáticas; e daria formação sistemática em Informática. Produziria Licenciados com formação e motivação próprias para trabalhar em Bioinformática e em Quimio-informática; mas forneceria também profissionais para empregos mais freqüentemente oferecidos nas áreas comerciais e de controle de qualidade de empresas químicas e farmacêuticas, e mesmo para empregos na área da informática.

Outra alternativa é a criação de um ramo de Bio- e Quimio-informática em Licenciaturas de Química ou Biologia. Mas será algum destes caminhos possível, em tempo de diminuição de número de alunos, num sistema universitário cansado de Licenciaturas com nomes novos e problemas velhos?

Mais fácil será talvez introduzir cadeiras de Quimio-informática nas licenciaturas de Química e criar cursos de formação profissional nesta área. Embora com nomes diversos, em várias universidades têm sido incluídas matérias de informática e computação em algumas disciplinas de Química, ainda que de forma pouco abrangente (existindo ainda licenciaturas em Departamentos nacionais de prestígio sem uma disciplina de Química Computacional). As aproximações já feitas são resumidamente as seguintes: 
a. Disciplinas de Química Teórica que tratam da teoria subjacente aos métodos de modelação molecular (química quântica, soluçôes aproximadas da equaçáo de Schrödinger, modelo de Hückel, método de Hartree-Fock). Incluem conteúdos de termodinâmica estatística, teoria de grupos e por vezes também de tratamento de erros.

b. Disciplinas de Química Computacional ou de Modelação Molecular que têm por vezes conteúdos sobreponíveis aos de cadeiras de Química Teórica. Incidem especialmente sobre: 1) aplicaçóes de cálculos quânticos e de campos de forças empíricos ao estudo de mecanismos reacionais e de iteraçóes ligando - receptor; 2) dinâmica molecular; 3) generalidades sobre sistemas operativos e programação.

c. Disciplinas de Quimiometria que tratam de aplicaçôes de estatística e redes neuronais à análise de dados químicos. Aplicações de referência são a classificação de amostras a partir de análises com múltiplas variáveis e o estabelecimento de relaçôes entre estrutura molecular e função.

d. Disciplinas de Documentação Científica que abordam para além das fontes tradicionais de informação 'em papel', as fontes de informação química na Internet e em suportes digitais.

e. Disciplinas de Química várias em cujos programas os docentes incluíram a utilização de software aplicado às respectivas matérias.

\subsection{Edição e visualização da Informação Química}

Através de editores moleculares (por exemplo, ChemDraw, ISIS Dra ou applets Marvin em Java) criam-se e editam-se ficheiros eletrônico contendo estruturas químicas. Estruturas 2D ou 3D de moléculas simples ou de macromoléculas, assim como cromatogramas ou espectros, são visualizados através de programas próprios, de que existem muitos exemplos, gratuitos ou comerciais.

Para apresentação de informação na WWW usam-se principalmente documentos HTML, que podem ser editados com editores próprios, e que podem incorporar, de forma interactiva, estruturas químicas $2 \mathrm{D}$ ou 3D e espectros, por exemplo utilizando o plug-in Chime para browsers de WWW. Tem sido desenvolvida uma linguagem própria para codificação de informação química (CML - Chemical Mark-up Language) tendo em vista sobretudo a Internet. Estruturas e propriedades moleculares podem ser visualizadas em ambiente de realidade virtual usando o formato VRML. Informaçáo química pode ser transmitida por email e reconhecida automaticamente pelo cliente de email de modo a utilizar editores ou visualizadores adequados. Tal é possível pela utilização de MIME químico.

\subsection{Arquivo de Informação Química}

A essência de uma estrutura molecular está na identidade dos seus átomos, nas ligaçóes que estabelecem entre si e na orientação espacial destas. Têm sido propostas várias maneiras de codificar esta informação e existem consequentemente vários formatos e tipos de ficheiros em que são arquivadas estruturas moleculares. Entre os mais comuns estão os ficheiros. Mol e .pdb. Também a informação espectroscópica é representada em formatos próprios que usam frequentemente estratégias para reduzir o tamanho dos ficheiros necessários. Há uma tendência para que o formato JCAMP se torne um padrão.

Volumes grandes de informaçáo arquivam-se de preferência em bases de dados. 
Existem vários sistemas para a construção de bases de dados com informação química (como o ChemFinder, ISIS Base, CACTVS, ACD SpecManager) que permitem arquivar estruturas químicas, raçôes, propriedades numéricas ou alfanuméricas, fórmulas, espectros. Vários tipos de pesquisas podem ser efetuada, sendo específicas da Química as pesquisas de sub-estruturas, de sub-espectros, de reações ou de semelhança estrutural. Através de bases de dados relacionais pode incorporar-se informação existente em várias bases de dados.

\subsection{Computação Química}

Através de métodos estatísticos e de redes neuronais é possível estabelecer correlações entre estrutura química e propriedade molecular (QSPR) ou entre estrutura química e atividade biológica (QSAR). Para tal, é frequente representar estruturas químicas por números, mais concretamente por um número fixo de parâmetros. Tem-se desenvolvido uma grande variedade de descritores moleculares baseados principalmente em grafos moleculares, em propriedades físico-químicas, ou em características geométricas.

A utilização de descritores moleculares, de impressóes digitais moleculares e de outros tipos de códigos permite analisar o grau de diversidade estrutural existente num conjunto de compostos, o que é frequentemente útil no design de bibliotecas combinatoriais. Por outro lado permite estabelecer medidas de semelhança estrutural entre duas ou mais moléculas.

A aplicação mais clássica da computação química consiste no recurso à mecânica molecular ou à mecânica quântica para o cálculo de propriedades termodinâmicas de compostos e reaçôes. Vários tipos de programas estão disponíveis, com aproximaçôes de vários níveis e têm tido muitas aplicações no design de fármacos e de raçôes.

Algoritmos muito utilizados são os algoritmos evolucionários, principalmente os algoritmos genéticos. Simulam a evolução de uma população em que os indivíduos com características mais desejáveis sobrevivem e reproduzem-se, fazendo sobressair, ao fim de várias geraçôes, as características que tornam os indivíduos mais aptos. São utilizados para problemas de otimização e têm tido aplicação desde a análise conformacional até a seleção de descritores moleculares mais adequados ao estabelecimento de QSAR.

\subsection{Bases de dados com Informação Bioquímica}

Estes tipos de bases de dados têm a especificidade de conterem principalmente estruturas 3D de macromoléculas biológicas, sequências (de aminoácidos ou ácidos nucléicos) e vias metabólicas. É de especial relevo neste contexto o projeto do genoma humano. A análise para extrair conhecimentos relevantes destas bases de dados envolve algoritmos e software para alinhamento de sequências, pesquisa de semelhanças, estimativa de árvores filogenéticas, previsão estrutural e inferência funcional.

\subsection{Fontes de Informação Química}

O aparecimento e onipresença da Internet vieram revolucionar as fontes de informação a que os químicos têm acesso. Para além de inúmeras fontes novas, também as antigas (revistas, enciclopédias, catálogos, índices) migraram ou tendem a migrar (pelo menos em regime complementar) para a Internet. Estão disponíveis bases de dados espectroscópicas e estruturais, 
toxicológicas e de segurança, de reações químicas, de propriedades moleculares e catálogos comerciais. Existem ferramentas comerciais de pesquisa bibliográfica (como o Chemical Abstracts ou o Beilstein), mas também sites gratuitos como o da Ingenta (herdeiro do BIDS e do Uncover) ou o Medline, e serviços de alerta. Outra fonte formidável de informação disponível gratuitamente na Internet e frequentemente esquecida nas Universidades são as bases de dados de patentes. E as revistas científicas tradicionais estão presentes na Internet com outras revistas exclusivamente eletrônica.

\section{Consideraçóes finais}

A Química aliada à informática tem trazido muitos benefícios tanto pra quem ensina como para quem aprende, pois a pesquisa mostrou a importância dessa ferramenta para tornar as aulas mais significativas e práticas.

A sala de aula deve deixar de ser o lugar das carteiras enfileiradas para se tornar um local em que professor e alunos podem realizar um trabalho diversificado em relação a conhecimento e interesse. O papel do professor deixa de ser o de "entregador" de informação para ser o de facilitador do processo de aprendizagem. O aluno deixa de ser passivo, de ser o receptáculo das informaçóes para ser ativo aprendiz, construtor do seu conhecimento. Portanto, a ênfase da educação deixa de ser a memorização da informação transmitida pelo professor e passa a ser a construção do conhecimento realizada pelo aluno de maneira significativa, sendo o professor o facilitador desse processo de construção.

O processo de repensar a escola e preparar o professor para atuar nessa escola transformada está acontecendo de maneira mais marcante nos sistemas públicos de educação, principalmente nas escolas de ensino médio de tempo integral. Nas escolas particulares o investimento na formação do professor ainda não é uma realidade. Nessas escolas a informática está sendo implantada nos mesmos moldes do sistema educacional dos Estados Unidos no qual o computador é usado para minimizar o analfabetismo computacional dos alunos ou automatizar os processos de transmissão da informação.

Embora as questôes envolvidas na implantação da informática na escola estejam mais claras hoje, as nossas açóes no passado não foram voltadas para o grande desafio dessas mudanças. Mesmo hoje, as ações são incipientes e não contemplam essas mudanças. Isso pode ser notadamente observado nos programas de formação de professores para atuarem na área da informática na educação que ainda hoje são realizados.

As experiências de implantação da informática na escola têm mostrado que a formação de professores é fundamental e exige uma abordagem totalmente diferente. Primeiro, a implantação da informática na escola envolve muito mais do que prover o professor com conhecimento sobre computadores ou metodologias de como usar o computador na sua respectiva disciplina. Existem outras barreiras que nem o professor nem a administração da escola conseguem vencer sem o auxílio de especialistas na área.

Por exemplo, dificuldades de ordem administrativa sobre como viabilizar a presença dos professores nas diferentes atividades do curso ou problemas de ordem pedagógica: escolher um assunto do currículo para ser desenvolvido com ou sem o auxílio do computador. Segundo, os assuntos desenvolvidos durante o curso devem ser escolhidos pelos professores de acordo com o 
currículo e a abordagem pedagógica adotadas pela sua escola.

É o contexto da escola, a prática dos professores e a presença dos seus alunos que determinam o que vai ser trabalhado pelo professor do curso. $\mathrm{O}$ curso de formação deixa de ser uma simples oportunidade de passagem de informação para ser a vivência de uma experiência que contextualiza o conhecimento que o professor constrói.

\section{Referências}

APPLE, M. W. Trabalho docente e textos: economia política das relaçóes de classe e de gênero em educaçáo. Artes Médica, 1995.

BOGDAN, R.; BIKLEN, S. Investigaçáo qualitativa em educaçáo: uma introduçáo à teoria e aos métodos. Porto editora, 1994.

CHASSOT, A. I. Alfabetização científica: questôes e desafios para a educação. Ed. Unijuí, 2003. FRIGOTTO, G. Tecnologia, relações sociais e educação. Tempo brasileiro, v. 105, 1991.

GIORDAN, M. O papel da experimentação no ensino de ciências. Química nova na escola, v. 10, n. 10, p. $43-49,1999$.

KENSKI, V. M. O professor, a escola e os recursos didáticos em uma sociedade cheia de tecnologias. Sáo Paulo, UNICAMP, 1994.

KENSKI, V. M. Educação e tecnologias: o novo ritmo da informação. 141 p. 2007.

LEAL, R. C. et al. A química quântica na compreensão de teorias de química orgânica. Química Nova, v. 33, n. 5, p. 1211-1215, 2010.

MALDANER, O. A. O professor-pesquisador: uma nova compreensão do trabalho docente. Espaços da Escola, v. 31, p. 5-14, 1999.

MALDANER, O. A. A formaçáo inicial e continuada de professores de química: professores/pesquisadores. Editora Unijuí, 2000.

MORTIMER, E. F.; SCOTT, P. Atividade discursiva nas salas de aula de ciências: uma ferramenta sociocultural para analisar e planejar o ensino. Investigaçóes em ensino de ciências, v. 7, n. 3, p. 283-306, 2016.

PAPERT, Seymour. A máquina das crianças. Porto Alegre: Artmed, v. 17, 1994.

PERRENOUD, P. Novas Competências para Enisnar: convite à viagem. (Trad. Patricia C. Ramos). Porto Alegre: Artmed, 10.

SANTOS, W. L. P. dos; SCHNETZLER, R. P. Educação em Química: Compromisso com a cidadania. 2 a. edição. Ijuí: Ed. UNIJUÍ, 2000.

VYGOTSKY, L. S. A formaçáo social da mente [The social formation of mind]. 1984.

VIGOTSKI, L. S. A construção do pensamento e da linguagem. Trad. Paulo Bezerra, v. 2, Martins Fontes; 1998. 